\title{
Two Distinct Rhythmic Motor Patterns Are Driven by Common Premotor and Motor Neurons in a Simple Vertebrate Spinal Cord
}

\author{
S. R. Soffe \\ Department of Zoology, Bristol University, Bristol BS8 1UG, United Kingdom
}

\begin{abstract}
Xenopus embryos show two distinct rhythmic motor patterns: swimming and struggling. Both can be generated by spinal cord circuitry and evoked by stimulation of a single skin sensory pathway (Soffe, 1991b). This presents a valuable opportunity to explore mechanisms for vertebrate motor pattern switching. Swimming and struggling have been compared using intracellular recording from spinal neurons in Immobilized embryos. Underlying synaptic drive was similar; motoneurons and premotor interneurons were excited in phase with ipsilateral motor root discharge and inhibited in phase with contralateral motor root discharge. Excitation was stronger during struggling and associated with short bursts of impulses, contrasting with single spikes per cycle during swimming. Excitation was reduced in both patterns by local application of $1 \mathrm{~mm}$ kynurenic acid, indicating excitatory amino acid mediation. Inhibition was antagonized by $1 \mu \mathrm{M}$ strychnine, indicating glycine mediation. Many motoneurons (76\%) and premotor interneurons $(68 \%)$ fired during both swimming and struggling, including examples of all three spinal premotor interneuron classes. Most of the remaining motoneurons $(20 \%)$ and premotor interneurons $(24 \%)$ fired only during struggling, providing roughly $30 \%$ more active neurons than during swimming. To investigate whether new neuronal classes become active during struggling, recordings were made from sensory neurons and sensory interneurons. Rohon-Beard sensory neurons did not fire during either swimming or struggling. Dorsolateral commissural sensory interneurons received rhythmic, strychnine-sensitive inhibition during both swimming and struggling and also did not fire. Neither of these neuronal classes is therefore recruited to the circuitry for struggling. Although behaviorally distinct, Xenopus embryo swimming and struggling motor patterns appear to employ similar synaptic drive. I propose that this reflects the common nature of much of the premotor circuitry that drives them. Extra neurons are recruited to this circuitry during struggling, but only from within classes that also participate in swimming.
\end{abstract}

[Key words: Xenopus embryo, motor pattern switching, swimming, sensory interneurons, premotor interneurons]

\footnotetext{
Received Jan. 22, 1993; revised Apr. 19, 1993; accepted Apr. 29, 1993.

This work was supported by the Medical Research Council (U.K.). I thank Drs. Jon Clarke, Nicholas Dale, and Alan Roberts for valuable discussion at various stages in this study, and Fiona Wyatt, Malcolm Holley, and Mark Shannon for technical help.

Correspondence should be addressed to S. R. Soffe, Department of Zoology, Bristol University, Woodland Road, Bristol BS8 1UG, UK.

Copyright (C) 1993 Society for Neuroscience $0270-6474 / 93 / 134456-14 \$ 05.00 / 0$
}

We now have detailed knowledge of the neuronal circuitry underlying many rhythmic behaviors. As a result, we can see that different but related patterns of motor output may or may not be driven by the same or overlapping sets of neurons. For example, bifunctional muscles and motoneurons are apparently driven by different premotor circuits for different patterns of swimmeret beating in crayfish (Heitler, 1985), walking and flight in the locust (Ramirez and Pearson, 1988), or locomotion and stridulation in the cricket (Hennig, 1990). Elsewhere, however, evidence suggests the neural substrates for different behaviors can have at least some components in common (Getting and Dekin, 1985; Hennig, 1989; Meyrand et al., 1991). There must therefore be considerable flexibility in the operation of some neural networks or individual circuits (Weimann et al., 1991). There must also be mechanisms to switch or select different patterns of motor output for different behaviors, perhaps by reconfiguring particular circuit elements. (Getting and Dekin, 1985; Getting, 1989).

Most of what we know about circuit flexibility derives from investigation of invertebrates. In vertebrates, relationships between neural circuits for different behaviors, or indeed the circuits themselves, are poorly understood. It has therefore not been possible to explore whether a similar degree of circuit flexibility is a feature of vertebrate neural control. Available evidence suggests that related circuitry drives walking and hatching in chicks (Bekoffet al., 1987), different forms of scratch in the turtle (Robertson et al., 1985; Mortin and Stein, 1989), and locomotion and scratching in the cat (Berkinblit et al., 1978; Gelfand et al., 1988), but in none of these cases is detailed information of the underlying neural circuitry available.

The Xenopus embryo shows two distinct rhythmic behaviors: swimming (Kahn et al,, 1982) and a stronger lashing movement termcd struggling (Kahn and Roberts, 1982b). Both are driven by the same muscles, the axial myotomes; both can be generated by neural circuitry within the spinal cord, and both can be evoked by stimulation of a single spinal sensory system (Soffe, 1991b). In addition, the neuroanatomy of the Xenopus embryo spinal cord is relatively simple and the few different neuronal classes it contains (Roberts and Clarke, 1982; Roberts, 1989) are now known in some detail. Much is already known of the neural activity underlying swimming (reviewed in Roberts et al., 1986; Soffe, 1991a). The preparation therefore presented an ideal opportunity to study the relationship between two motor patterns, to determine how neural circuitry drives them, and to ask ultimately how switching between the two motor behaviors occurs.

I have here made recordings from Xenopus embryo spinal cord neurons to determine the pattern of activity during strug- 
gling and reveal which neurons control its motor output. Members of three neuron classes, motoneurons, excitatory interneurons, and inhibitory commissural interneurons, contribute to swimming (Roberts et al., 1986; Soffe, 1991a). Because of the relative simplicity of the embryo spinal cord, it seemed likely that at least some common premotor elements would also contribute to struggling. I have now established this directly. I have also recorded from two further classes of neurons, Rohon-Beard sensory neurons and sensory interneurons, that do not usually fire during swimming (Clarke and Roberts, 1984; Roberts and Sillar, 1991), to establish whether they may be recruited to the circuitry during struggling. Brief Rohon-Beard neuron firing triggers swimming by strongly exciting dorsolateral sensory interneurons to fire (Clarke and Roberts, 1984; Roberts and Sillar, 1991). It seemed probable, by extension, that repetitive RohonBeard neuron stimulation to evoke struggling would produce sustained excitation and thus repetitive firing in sensory interneurons during struggling (Soffe, 1991b). These sensory interneurons could therefore be recruited to the circuitry for struggling. My results indicate that these additional neuronal classes do not fire during struggling. Thus, two distinct motor patterns in this simple vertebrate appear to involve essentially the same circuitry operating in two different ways. My evidence suggests that the switch to struggling involves recruitment of neurons from within classes already participating in swimming rather than otherwise inactive types.

\section{Materials and Methods}

Stage 37/38 (Nieuwkoop and Faber, 1956) Xenopus laevis embryos were obtained by induced pairing. For making recordings they were paralyzed with $80-100 \mu \mathrm{M} d$-tubocurarine (Sigma) and superfused with saline containing $\mathrm{NaCl}, 105.0 \mathrm{~mm} ; \mathrm{KCl}, 2.5 \mathrm{~mm} ; \mathrm{CaCl}_{2}, 4.0 \mathrm{~mm} ; \mathrm{MgCl}_{2}, 1.0$ $\mathrm{mM} ; \mathrm{NaHCO}_{3}, 15 \mathrm{~mm}$; and maintained at pH 7.2 by constant bubbling with $5 \% \mathrm{CO}_{2}, 95 \% \mathrm{O}_{2}$, at temperatures between $18^{\circ} \mathrm{C}$ and $22^{\circ} \mathrm{C}$.

The skin was removed from areas overlaying some of the trunk myotomes to allow extracellular recording of activity from motor axons with suction electrodes placed in the clefts between myotomes (cf. Kahn and Roberts, 1982a; myotomes numbered from the rostral end as for Fig. 1 of Soffe, 1989). Such motor root recordings were usually made rostral and caudal on the right side to monitor longitudinal coordination, though some were made additionally from the left side. Some trunk skin including the dorsal fin was always left intact for electrical stimulation (see below). For intracellular recording, portions of overlying myotome were removed from two to five segment lengths of the spinal cord on the right side. Intracellular recordings were made using microelectrodes filled with either $3 \mathrm{~m}$ potassium acetate or 1-5\% HRP (grade I, Boehringer) in $0.5 \mathrm{~m}$ potassium acetate with $10 \mathrm{~mm}$ HEPES adjusted to $\mathrm{pH}$ 7.4. HRP was applied iontophoretically, using $0.2-0.3 \mathrm{nA}$ squarc depolarizing pulses at $0.5 \mathrm{~Hz}$ for $10-20 \mathrm{~min}$, and visualized as described previously (Soffe et al., 1984). All intracellular recordings were made on the right side, at levels between the second and tenth segment.

Electrical stimuli were delivered either singly or in trains using a suction electrode applied to the trunk skin on the right side. The electrode was usually placed over the yolk sac (ventral to the myotomes) at the rostral or mid-trunk. Pulse widths of $0.1-1.0 \mathrm{msec}$ were used, up to a maximum current of approximately $20 \mu \mathrm{A}$. Electrical artifacts were electronically "blanked" from recordings during repetitive stimulation (Soffe, 1991b). Data were recorded conventionally, stored on tape, and plotted using either a thermal arraycorder (Graphtek WR7600) or a digital oscilloscope (Gould 1425) and digital plotter (HP Color-Pro).

Pharmacological agents strychnine sulfate and kynurenic acid (Sigma) were microperfused onto local regions of the CNS through separate fine polyethylene tubes, exiting through a common orifice (approximately $100 \mu \mathrm{m}$ tip opening).

Recorded neurons are considered in this study under four main groups that include all the differentiated neuronal classes currently recognized in the spinal cord (Roberts and Clarke, 1982; Roberts, 1989). Provisional characterization was on the basis of position in the spinal cord and/or physiological criteria. Neurons lying in the ventral quarter of the spinal cord are predominantly motoneurons (Roberts and Clarke, 1982; Soffe and Roberts, 1982a), and recordings made in this region were considered to be from probable motoneurons (see Soffe, 1990). Premotor interneurons predominantly occupy regions outside the ventral quarter, and recordings made on or above the dorsoventral midline, which also showed the typical pattern of synaptic drive during swimming (for review, see Soffe, 1991a), were considered to be from thesc ncurons. In eight cases it was possible to provide a direct characterization following intracellular HRP marking. Sensory interneurons were characterized on positional and physiological grounds (Roberts and Clarke, 1982; Clarke and Roberts, 1984; Roberts and Sillar, 1991). Dorsolateral commissural sensory interneurons were identified by their dorsolateral superficial position, short-latency EPSPs to ipsilateral skin stimulation, and the presence of almost exclusively on-cycle IPSPs during swimming. RohonBeard sensory neurons were identified by their very dorsal location in the spinal cord, high $(>80 \mathrm{mV})$ resting potential, large-amplitude impulse in response to a depolarizing current step and relatively low input resistance. Results are based on successful recordings from 110 neurons in 71 embryos.

\section{Results}

Characteristics of fictive swimming and fictive struggling motor patterns

As shown previously (Soffe, 1991b), electrical stimulation of the trunk skin of Xenopus embryos immobilized with $d$-tubocurarine evoked "fictive" swimming and "fictive" struggling motor patterns (patterns appropriate to drive behavioral swimming and struggling, respectively; Kahn and Roberts, 1982b; Kahn et al., 1982). Single, or brief trains of, stimuli evoked episodes of swimming that far outlasted the period of stimulation. Struggling was evoked during periods of repetitive stimulation, either preceding or during an episode of swimming, and did not usually far outlast stimulation (Fig. 1 $A$ ). As described previously (Soffe, $1991 \mathrm{~b}$ ), the two patterns recorded from motor roots were quite distinct: rhythmic single spikes alternated between the two sides and passed from head to tail during swimming, and rhythmic bursts of discharge alternated between the two sides and passed from tail to head during struggling (Fig. 1A).

\section{Patterns of activity in motoneurons}

To examine the activity of individual neurons during struggling and swimming, intracellular recordings were made from 25 presumed motoneurons (see Materials and Methods). The patterns of activity during swimming and struggling in these neurons were quite different. During each cycle of swimming, motoneurons fired a single impulse (if they fired at all; see below) in phase with motor root discharge on the same side (Figs. 1, 2A). This impulse rides on top of a brief, on-cycle EPSP (Dale and Roberts, 1985; for review, see Soffe, 1991a). Starting in the middle of each cycle, in phase with motor root discharge on the opposite side there was a midcycle IPSP (arrowed, Fig. 1B).

During each cycle of struggling, the membrane potential first depolarized in phase with motor root discharge on the same side (Fig. 1B). It then returned from this "depolarized phase" to close to or below the resting potential in a "hyperpolarized phase" coincident with motor discharge on the opposite side. During the depolarized phase, the membrane potential trajectory was quite different from that during swimming. In swimming, membrane potential fell to a depolarized "plateau" following the single spike on each cycle. In struggling, membrane potential remained strongly depolarized for a prolonged period and neurons fired up to a maximum of seven impulses. The mean level of depolarization, measured relative to the resting potential, was up to twice as high during struggling as during swimming (mean, $26 \pm 14 \%$ higher; $n=9$ ). During swimming, 
$A$ (i)
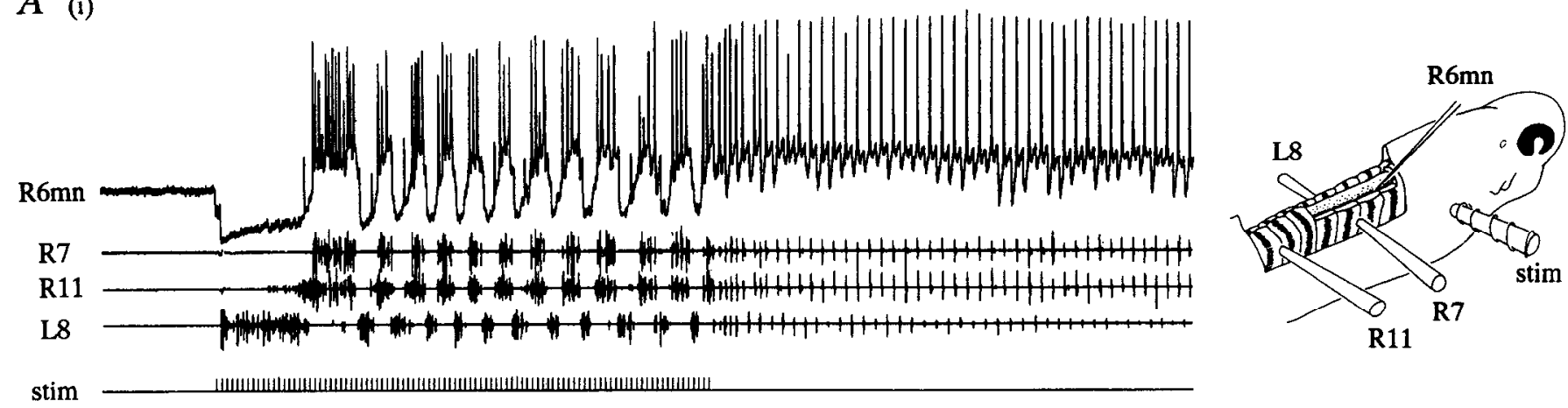

(ii)
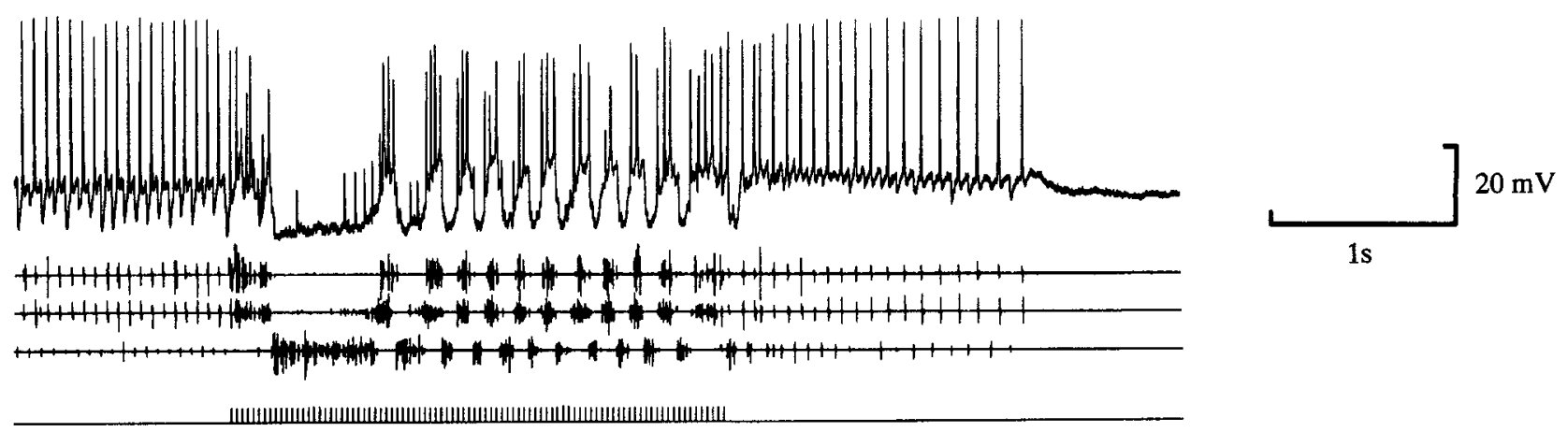

1s

$\boldsymbol{B}$
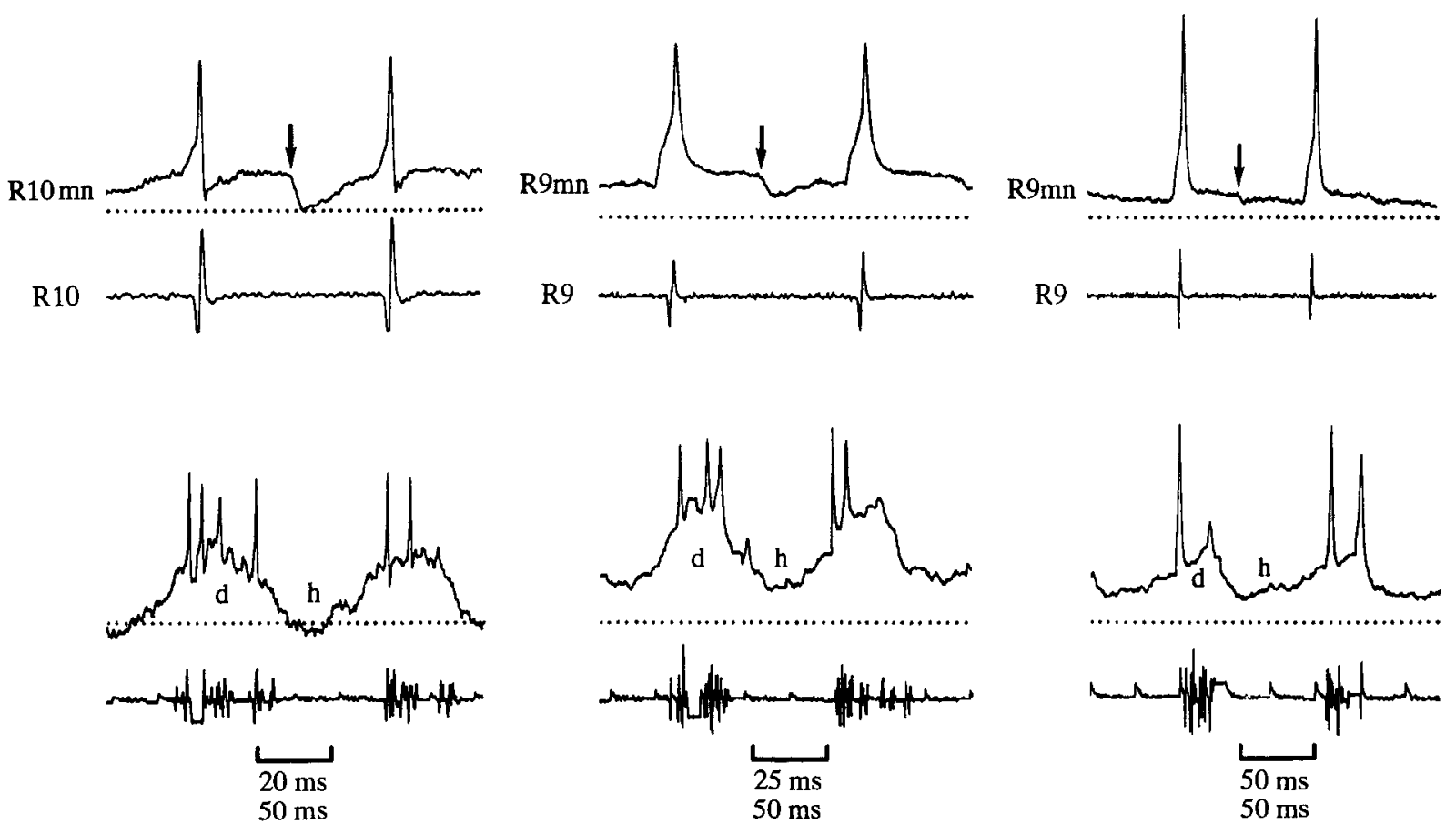

Figure 1. Swimming and struggling motor patterns. $A$, Intracellular recording from a presumed motoneuron on the right side of the sixth postotic segment $(R 6 m n)$ and extracellular recordings from motor roots on the right $(R 7$ and $R I l)$ and the left $(L 8)$ side (see inset diagram). Activity was evoked by electrical stimulation of the rostral trunk skin on the right side (stim). Repetitive stimulation evokes the struggling motor pattern, for approximately the duration of the stimulus, followed by swimming. This occurs either at the start (i) or during an ongoing episode of activity (ii). Head-to-tail delay in the onset of motor root bursts during swimming is not clear at this time scale. $B$. Comparison of membrane potential trajectories during swimming and struggling in three further motoneurons. The time scale for swimming traces has been expanded so that one cycle approximately 
the timing of on-cycle firing and the onset of the midcycle IPSP were highly synchronous (Fig. $1 B$ ). During struggling, the timing of depolarized and hyperpolarized phases was less clearly defined; membrane potential followed a more smoothly fluctuating trajectory between the two phases. Overall, the pattern of activity during struggling was more reminiscent of rhy thmic motor patterns typically seen in other animals (e.g., cat walking, Jordan, 1983; lamprey swimming, Grillner et al., 1991) than that during embryo swimming.

In some cases, the membrane potential during struggling showed a progressive depolarizing shift (asterisk, Fig. $2 A$ ). It was not clear whether this was due to a slow increase in the magnitude of depolarization, a decrease in the midcycle hyperpolarization, or both.

In response to intracellular injection of sustaincd current, the peak-to-peak amplitude of membrane potential changes underlying struggling did not alter greatly (Fig. $2 A$ ). However, the peak of the depolarizing phase, measured relative to the resting potential between episodes, became less positive with depolarization and more positive with hyperpolarization. Similarly, the trough of the hyperpolarizing phase became more negative with depolarization and less negative with hyperpolarization. Interestingly, artificial depolarization could lead to extra spikes during struggling (Fig. $2 A$ ) but only rarely during swimming. Also, neurons still spiked during struggling when hyperpolarized sufficiently to prevent firing during swimming (Fig. $2 A$ ).

Motoneuron input resistance was decreased throughout struggling, shown by reduction in the amplitude of responses to injected constant-current hyperpolarizing pulses (Fig. 2B). Because of the long membrane time constant of spinal neurons (Soffe, 1990), responses to these injected pulses did not asymptote and the absolute fall in input resistance could not be measured. The resistance decrease appeared larger while neurons were relatively hyperpolarized after midcycle, although it was harder to assess while neurons were firing during the depolarizing phase.

The shape of the membrane potential changes during struggling, together with the decrease in input resistance and the responses to current injection, was consistent with an alternating pattern of excitation and inhibition as described previously during swimming (for reviews, see Roberts et al., 1986; Soffe, 1991a). The nature of synaptic drive to motoneurons was therefore examined in more detail in six probable motoneurons using local perfusion of pharmacological agents. Recordings were made caudally between the sixth and ninth segments. Applications of pharmacological blockers were made at the same caudal levels (inset, Fig. 3A) so that more rostral regions, and hence both sensory activation and generation of the struggling rhythm, would be minimally affected. This approach was similar to that of the "partitioned preparation" adopted by Dale and Roberts (1984) in their study of excitation during swimming. During swimming, brief, caudal application of $1 \mathrm{~mm}$ kynurenic acid, a broad-spectrum excitatory amino acid antagonist, was sufficient to block motor root discharge and firing in individual motoneurons nearby within the spinal cord (Fig. 3). It also reduced the amplitude of the underlying on-cycle excitation (Fig. $3 B, C$ ). Caudal ap- plication had no clear effect on rostral discharge. During struggling, the same brief application was insufficient to abolish caudal motor root discharge, though it could weaken the rhythmic motor bursts (Fig. 3B). At the same time it reduced the mean level of depolarization (mean reduction to $63 \pm 4 \%$ of control level, $n=4$ ). The reduction in the depolarizing phase in individual neurons was sufficient to restrict or prevent their firing (Fig. 3B,C). Interestingly, kynurenic acid application also made the trough of the hyperpolarizing phase during struggling less depolarizing, suggesting that excitation lasts throughout each cycle. Longer, local applications of kynurenic acid were not investigated here, but sustained bath application of $1 \mathrm{~mm}$ kynurenic acid abolished all rhythmic activity in a reversible way. However, this was probably due both to a direct effect on the motor system and to blockage of the sensory pathway, which also involves a glutamate-like neurotransmitter (Sillar and Roberts, 1988). These findings indicate that excitatory amino acidmediated excitation is involved during both struggling and swimming, though they do not rule out the possibility of other excitation.

Brief, local application of $1 \mu \mathrm{M}$ strychnine at caudal levels reversibly blocked midcycle IPSPs during swimming but had no other obvious effect on the motor pattern (Fig. $4 A, B$ ). During struggling, the same application reduced the hyperpolarizing phase, and neurons remained more depolarized throughout each cycle (Fig. $4 B$ ). Brief applications of strychnine insufficient to disrupt the swimming pattern could produce a partial breakdown in the rhythmicity of firing during struggling, with impulses starting to appear throughout each cycle. This partial disruption also extended to rostral motor roots. More prolonged application usually led to a complete disruption of the struggling pattern, though the swimming pattern remained intact. The midcycle hyperpolarizing phase during struggling therefore involves glycinergic inhibition, like midcycle inhibition during swimming (Soffe, 1989; Dale et al., 1990). Weakening this inhibition has more profound effects on the struggling rhythm than on swimming

\section{Firing activity in premotor interneurons and motoneurons}

Recordings made from motoneurons suggested that the pattern of synaptic drive during struggling is similar to that during swimming. Both show excitation, at least partially mediated by an excitatory amino acid neurotransmitter, and midcycle glycinergic inhibition. Are the two patterns driven by similar or different circuitry? To explore this, the possible source of synaptic drive during struggling was investigated by recording from premotor interneurons.

Intracellular recordings were made from 25 presumed premotor interneurons on or just above the dorsoventral midline of the spinal cord (see Materials and Methods). Eight of these were subsequently characterized following intracellular HRP marking (Fig. 5). Two had morphology characteristic of presumed excitatory descending interneurons, five neurons had the morphology of glycinergic inhibitory commissural interneurons, and one had the morphology of an ascending interneuron (Roberts and Clarke, 1982; Soffe et al., 1984; Dale, 1985). All the

overlaps the equivalent struggling cycle. Notice during swimming a single spike per cycle in phase with each brief motor root burst and a midcycle IPSP (arrowed), and during struggling a prolonged depolarizing phase (d) leading to firing in phase with each prolonged motor root burst alternating with a hyperpolarizing phase $(h)$. Resting potential between episodes is shown dotted. Apparent fractionation of struggling bursts during electrical stimulation in this and subsequent figures results from artifact blanking (see Materials and Methods). 
$A$

(i)

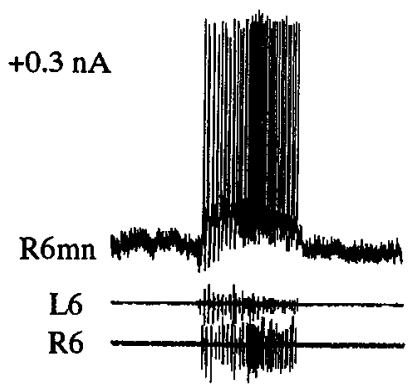

$0.0 \mathrm{nA}$

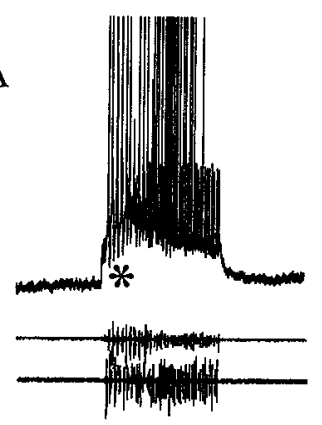

$-0.2 \mathrm{nA}$

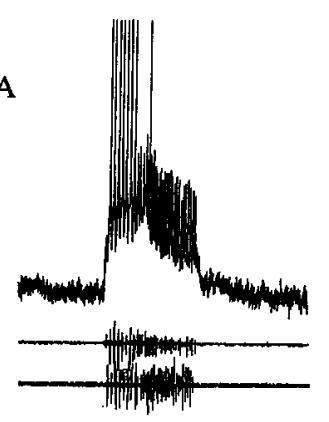

(ii)
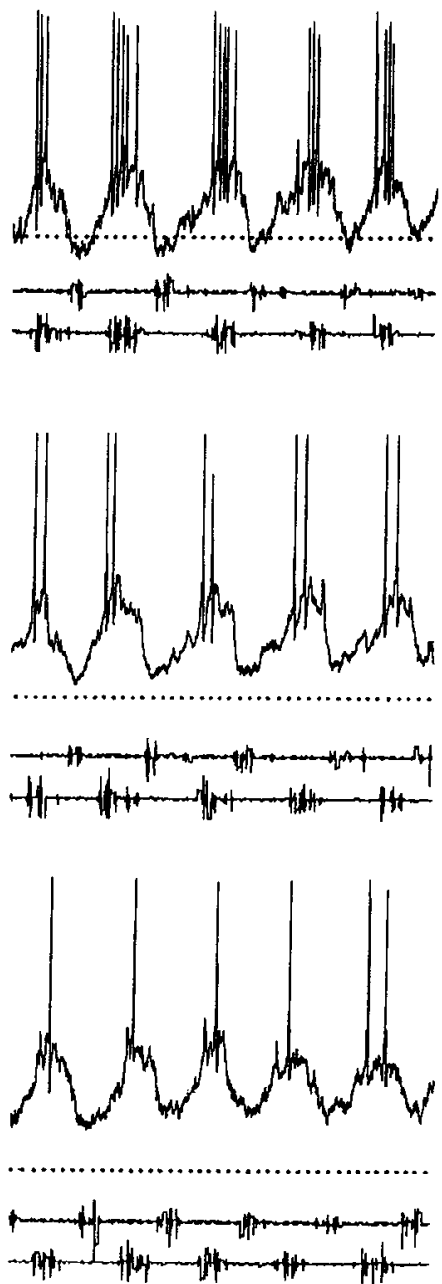

(iii)
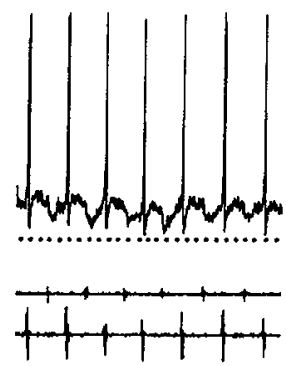

(i) $2 \mathrm{~s}$

(ii,iii) $200 \mathrm{~ms}$
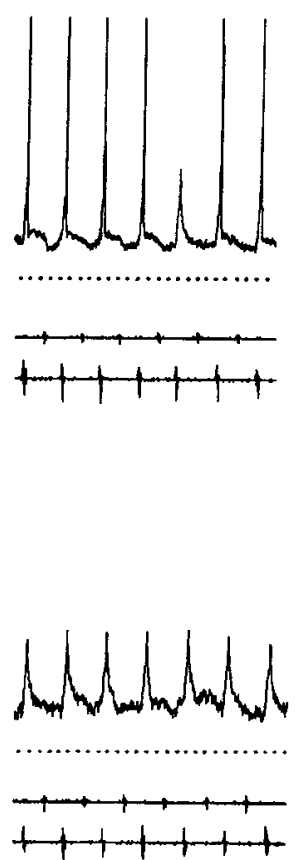

(ii)
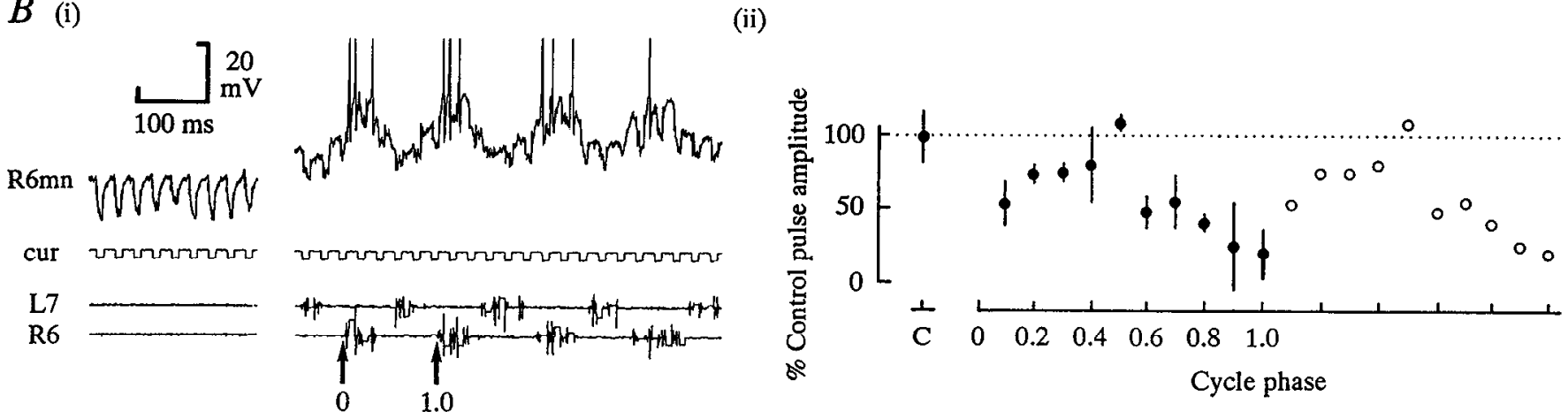

Figure 2. Responses to current injection and input resistance changes during struggling. $A$, Intracellular recording from a sixth postotic segment presumed motoneuron $(R 6 \mathrm{mn})$ together with motor root records $(L 6, R 6)$. Resting potential between episodes is shown dotted. Records shown are whole episodes of activity consisting of initial periods of struggling, evoked by repetitive electrical stimulation of the skin, followed by swimming (i); and expanded periods of struggling (ii) and swimming (iii) taken from the same episodes. See Results for details. Notice that depolarization produces an increase in spiking on each cycle during struggling but not swimming. Also, hyperpolarization sufficient to prevent firing during swimming does not do so during struggling. Notice also in $i$ a progressive depolarization during struggling $\left({ }^{*}\right)$. B:i, Membrane potential responses to constant current $0.1 \mathrm{nA}$ hyperpolarizing pulses (cur), injected into a sixth postotic segment presumed motoneuron (R6mn), are reduced in amplitude during struggling. Phases are arrowed for one cycle. $i i$, Response amplitude (mean \pm SE) plotted as percentage of control against cycle phase is decreased, indicating a fall in input resistance at all phases of the cycle (except 0.5 ) that is greatest after midcycle. Data are plotted twice to show the cyclic nature of the change. 
recordings from presumed and characterized premotor interneurons showed activity during swimming and struggling very much like that described above for motoneurons (Figs. 5, 6).

Many premotor interneurons $(68 \%, 17$ of 25$)$ fired impulses during swimming (Figs. 5, 6A). The remainder either did not fire or did so only rarely ( $<10 \%$ of cycles) (Fig. $6 B$ ). These remaining neurons received rhythmic synaptic drive during swimming and fired on-cycle spikes if injected with a low level of depolarizing current. In addition, some would fire on a few cycles of swimming if extra sensory stimulation was applied to increase the excitation, such as by dimming the illumination to stimulate the pineal photoreceptor pathway (Roberts, 1978).

All the premotor interneurons that fired during swimming also fired during struggling. However, in addition, most of those that fired rarely or not at all during swimming did fire during struggling. The resulting total of $92 \%$ (23 of 25 ) of premotor interneurons firing during struggling represented a recruitment of roughly $35 \%$ more neurons than during swimming. Of the eight morphologically characterized neurons, one commissural interneuron fired during struggling, but only fired during swimming if depolarized. The rest all fired during both swimming and struggling (Fig. 5).

The numbers of motoneurons firing also increased from $76 \%$ (19 of 25) during swimming to $96 \%$ (24 of 25) during struggling, an increase of roughly $25 \%$.

\section{Activity in sensory interneurons}

Recordings from presumed motoneurons and premotor interneurons indicated that while many are active during both swimming and struggling, some are additionally recruited during struggling. A further possibility remained that cntircly ncw classes of neurons also contribute to struggling. Of these, the most likely candidates were the sensory interneurons since these receive strong excitation from Rohon-Beard sensory neurons. Recordings were therefore made from 17 dorsolateral commissural interneurons, apparently by far the more numerous of the two types of sensory interneuron (Roberts and Clarke, 1982). They were identified by position and physiology (see Materials and Methods). In no case did dorsolateral commissural interneurons fire during either swimming or struggling (Fig. 7) even when depolarized by current injection. Instead, they were strongly inhibited throughout struggling by IPSPs that often fused from cycle to cycle to produce a sustained hyperpolarization (Fig. $7 B)$.

Inhibition of dorsolateral commissural interneurons during both swimming (cf. Sillar and Roberts, 1992) and struggling was reversibly antagonized by brief local application of $1 \mu \mathrm{M}$ strychnine (Fig. 8) and is therefore presumed to be glycinergic, like the inhibition of motoneurons.

During this study, no recordings were made from the second class of spinal sensory interneurons, the apparently far less numerous dorsolateral ascending interneurons. Their activity during struggling therefore remains unknown. However, their similarity to dorsolateral commissural interneurons during swimming (Roberts and Sillar, 1991) suggests that they too will be strongly inhibited.

\section{Activity of Rohon-Beard sensory neurons}

The last major category of spinal cord neurons, which could in principle be recruited during struggling, is the Rohon-Beard sensory neurons. Some, of course will be driven to fire by direct stimulation of their peripheral neurites when struggling is evoked through skin stimulation. However, to examine whether others were active, intracellular recordings were made from 42 RohonBeard neurons, identified by position and physiology (see Materials and Methods). In all cases, peripheral neurites of these neurons would have been cut when the spinal cord was exposed for intracellular recording, preventing direct stimulation from the skin. None fired during either swimming or struggling. Rohon-Beard neurons are therefore not centrally driven to fire during struggling and, like dorsolateral commissural interneurons, appear not to be recruited to the circuitry for struggling.

\section{Discussion}

This study has compared the activity of Xenopus embryo spinal neurons during its two main rhythmic behaviors, struggling and swimming. Both of these behaviors can be driven by circuitry within the spinal cord and evoked by the same spinal sensory pathway (Soffe, 1991b). I have now shown that the two patterns appear to involve similar synaptic drive and to be generated by largely common circuitry, with extra neurons being recruited during struggling from within the same rather than from new neuronal classes. It is now possible to start to explore in this simple vertebrate preparation the relationship between two quite different motor patterns, to ask what differences do exist between the ways the spinal neural circuitry drives them both, and eventually to ask how switching occurs between them.

\section{Patterns of synaptic drive during swimming and struggling}

Previous accounts of the synaptic drive to motoneurons and premotor interneurons during swimming have distinguished three main components: a "phasic" on-cycle EPSP often driving a single spike, a midcycle IPSP, and a "tonic" or background excitation on which the other two are superimposed (Soffe and Roberts, 1982b; Soffe et al., 1984; Dale, 1985; Dale and Roberts, 1985). This pattern probably involves the activity of just two classes of premotor interneuron (for reviews, see Roberts et al., 1986; Soffe, 1991a). The phasic and tonic excitation apparently result from dual-component EPSPs from a single class of excitatory premotor interneuron on the same side of the cord, the descending interneurons (Roberts and Clarke, 1982; Dale and Roberts, 1985). Short-duration non-NMDA receptor-mediated potentials provide the phasic component and long-duration NMDA receptor-mediated potentials summate to provide the tonic or background excitation (Dale and Roberts, 1985). The IPSP derives from a single class of glycinergic premotor interneurons on the opposite side of the cord, the commissural interneurons (Roberts and Clarke, 1982; Soffe et al., 1984; Dale, 1985; Dale et al., 1986).

Although the overall pattern of activity in motoneurons during struggling is quite distinct from that of swimming, the pattern of synaptic drive is similar: the depolarizing phase represents on-cycle excitation driving spikes and the hyperpolarizing phase represents midcycle inhibition. The influence of kynurenic acid suggests that excitation lasts throughout each cycle, and that the pattern is not, therefore, a simple alternation between excitation and inhibition but, like swimming, a background excitation on which stronger excitation and inhibition are superimposed. A similar pattern of synaptic drive underlies locomotor rhythms in cat (Jordan, 1983) and lamprey (Grillner et al., 1991).

\section{Which neurons participate in swimming and struggling?}

The Xenopus embryo spinal cord appears to contain only seven neuronal classes (Roberts and Clarke, 1982; Roberts, 1989): the 
A

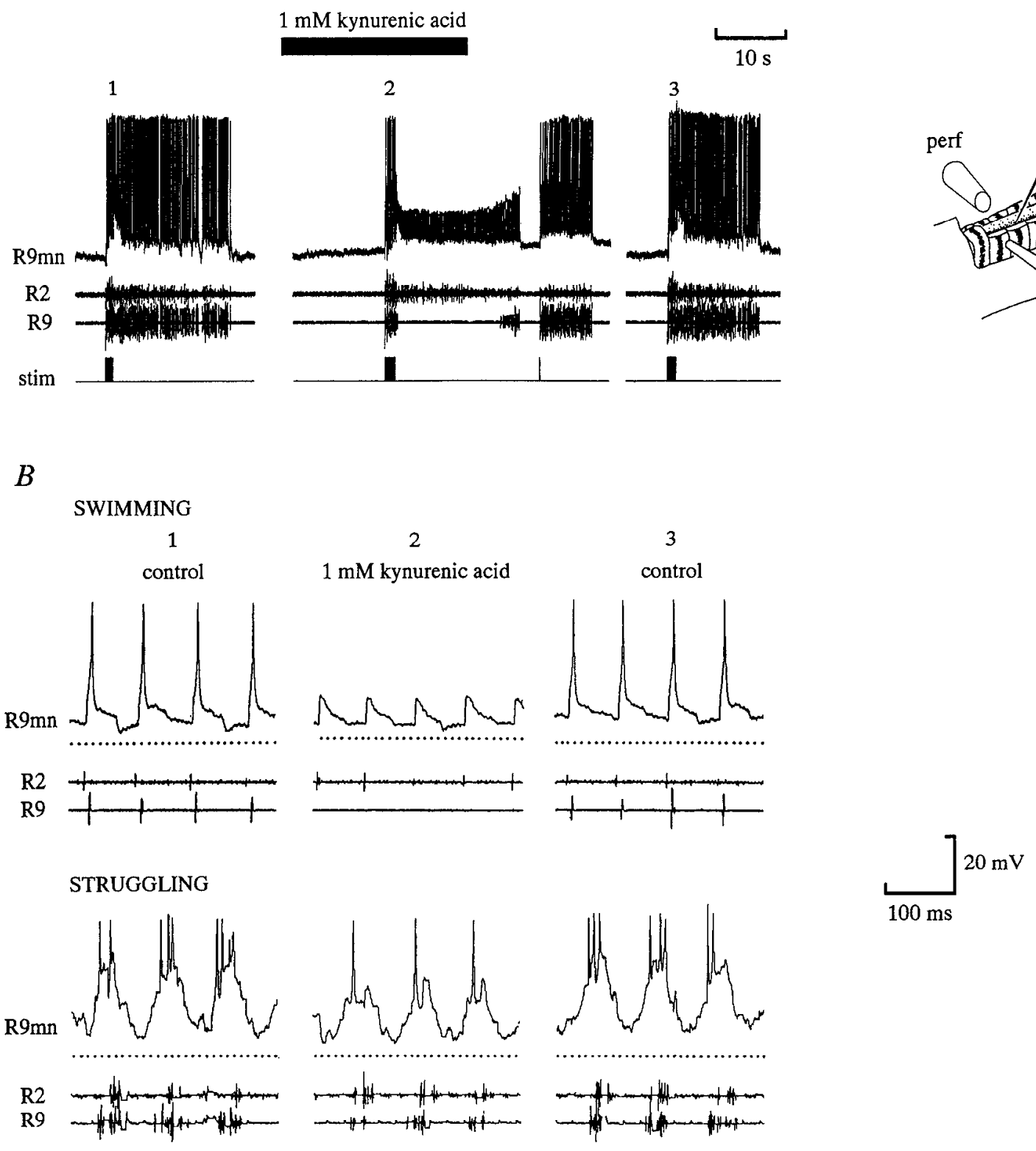

C

SWIMMING

control

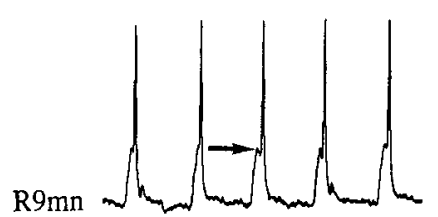

R9

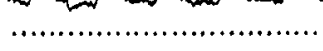

9

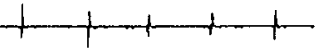

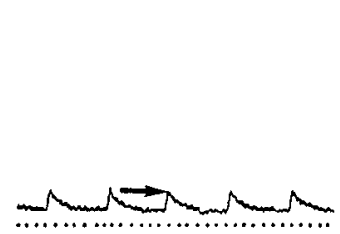

$1 \mathrm{mM}$ kynurenic acid

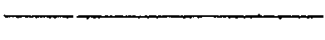

STRUGGLING

control

$1 \mathrm{mM}$ kynurenic acid
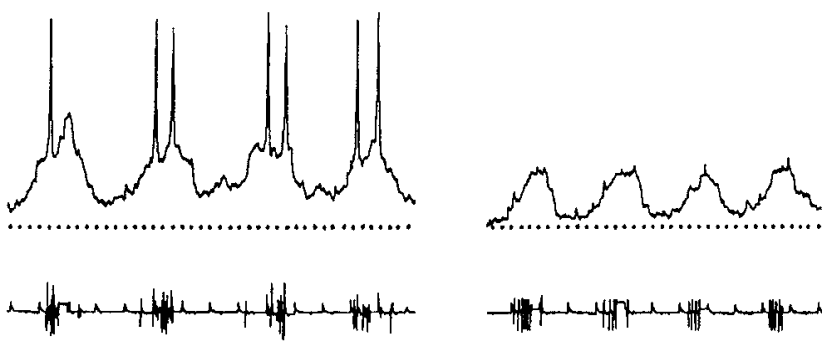

Figure 3. Effect of local application of kynurenic acid during struggling and swimming. $A$, Slow record showing results of single application of 1 mM kynurenic acid. Episodes $1-3$ each start with a sequence of struggling evoked by repetitive stimulation of the trunk skin (stim). One episode 
$A$

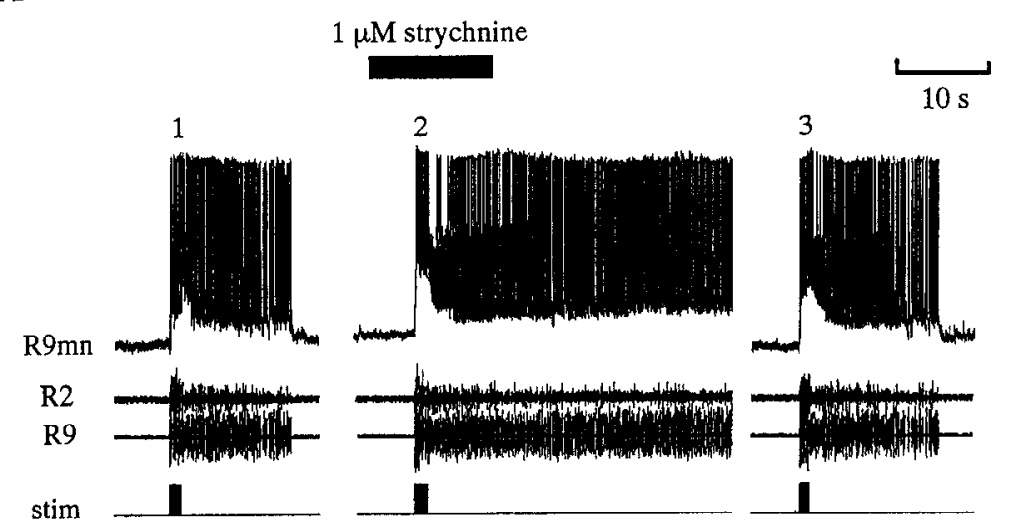

$B$

SWIMMING

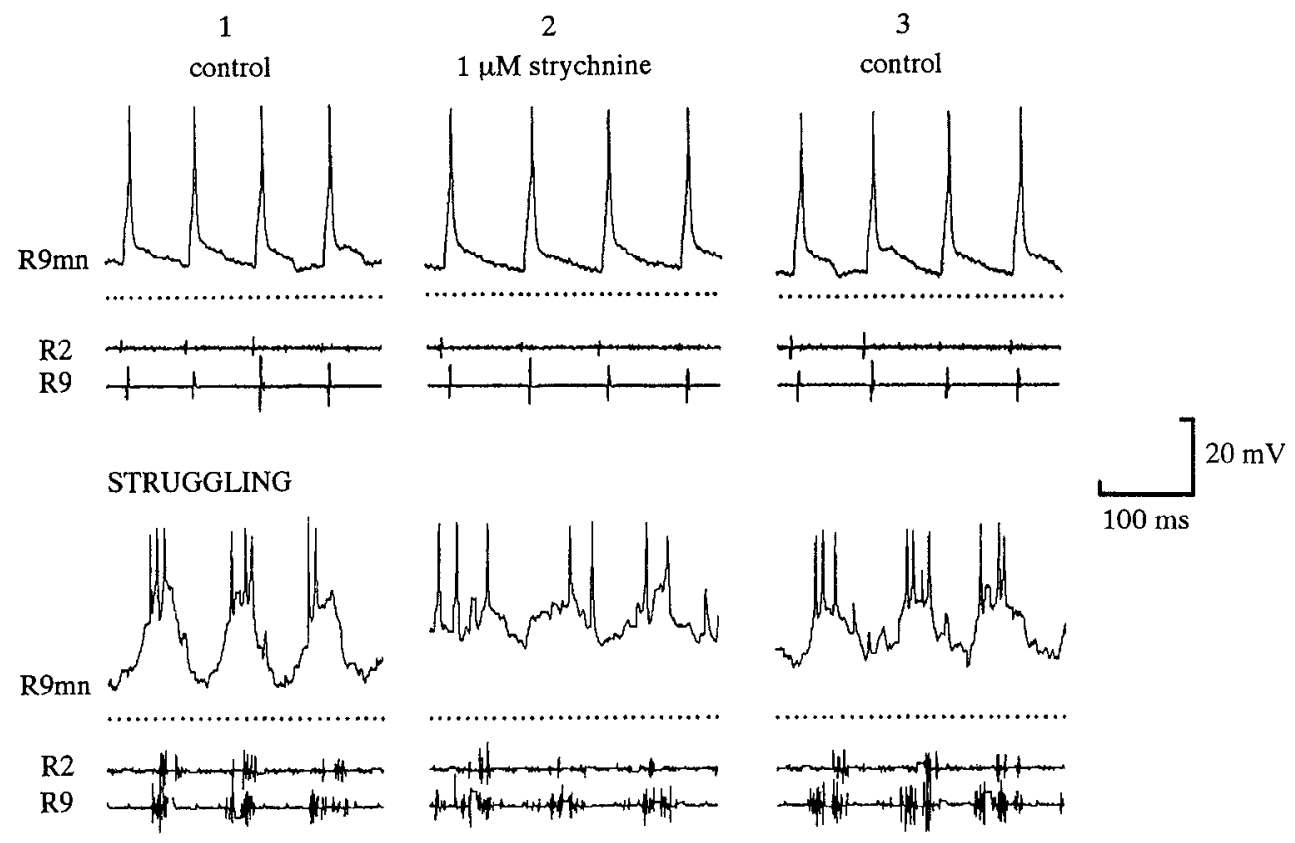

Figure 4. Effect of local application of strychnine during struggling and swimming. $A$, Recorded as for Figure $3 A$; each episode $1-3$ starts with a sequence of struggling evoked by repetitive stimulation of the trunk skin (stim). $B$, Expanded sequences from episodes $1-3$. Brief application of $1 \mu \mathrm{M}$ strychnine during swimming (episode 2 ) reversibly blocks midcycle inhibition but does not disrupt the rhythm. The same application during struggling reversibly blocks midcycle inhibition and produces a partial breakdown of the pattern. During recovery (episode 3 ), struggling is clearly reestablished even with inhibition still partly blocked.

motoneurons plus three classes of premotor interneurons, and also the primary sensory Rohon-Beard neurons plus two classes of sensory interneurons. For completeness, there is also a class of cerebrospinal fluid-contacting cells of unknown function, the Kolmer-Agdhur cells (Dale et al., 1987). Like previous findings (for reviews, see Roberts et al., 1986; Soffe, 1991a), this study has shown that only the motoneurons and presumed premotor interneurons fire during swimming. In the absence of any evidence for graded release in the embryo, these are the neurons that must make up the circuitry that drives the swimming pattern. It now appears that these are also the neurons that drive struggling.

A key finding of this study has been that neurons that fire during swimming (about 75\%) also fire during struggling. This included both motoneurons and anatomically characterized examples of all three classes of premotor interneuron (descending, commissural, and ascending interneurons), in addition to other presumed, though uncharacterized, premotor interneurons. None

of swimming alone between 2 and 3 was initiated by a single stimulus. Intracellular recordings from a ninth postotic segment presumed motoneuron together with rostral $(R 2)$ and caudal $(R 9)$ motor root records from the same side (see inset diagram). $B$, Expanded sequences from episodes $1-3$. Resting potential between episodes is shown dotted. Both during swimming (upper traces) and preceding struggling (lower traces), the neuron is depolarized and fires "on-cycle," and is relatively hyperpolarized "midcycle." Brief application of 1 mm kynurenic acid (episode 2) reduces the amplitude of excitation during swimming, prevents firing, and blocks caudal motor root discharge. The same application during struggling reversibly reduces the amplitude of depolarization, though it neither prevents firing nor blocks caudal motor root discharge. $C$, Recording from a different presumed motoneuron in a second embryo. Application of $1 \mathrm{~mm}$ kynurenic acid prevents firing and reduces the underlying excitation during both swimming (arrows) and struggling. Caudal motor root discharge is again blocked during swimming but only weakened during struggling. 
A

DESCENDING INTERNEURONE
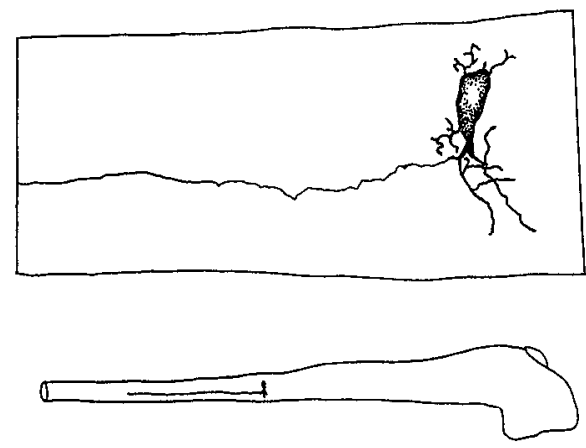

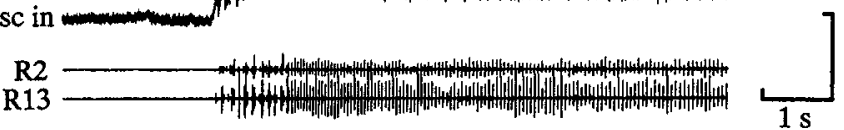

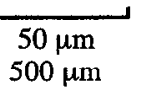
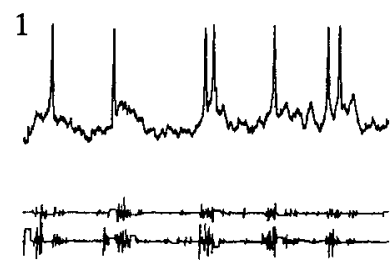

2 $100 \mathrm{~ms}$
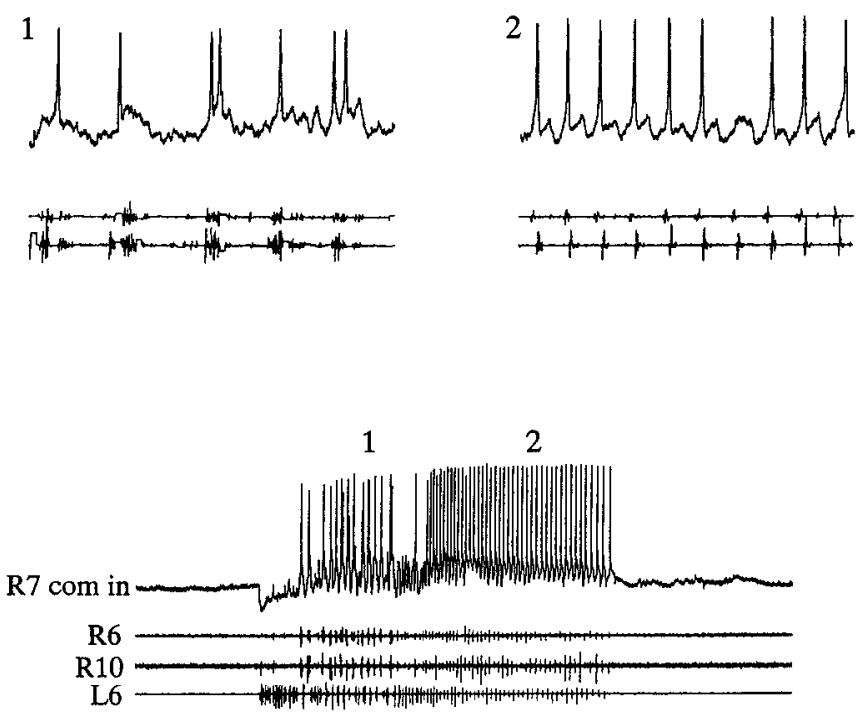

$50 \mu \mathrm{m}$
$500 \mu \mathrm{m}$

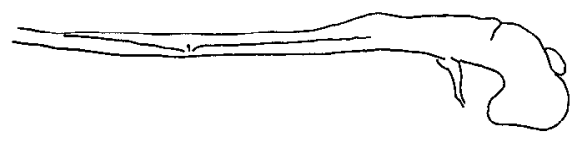

1

L6

等
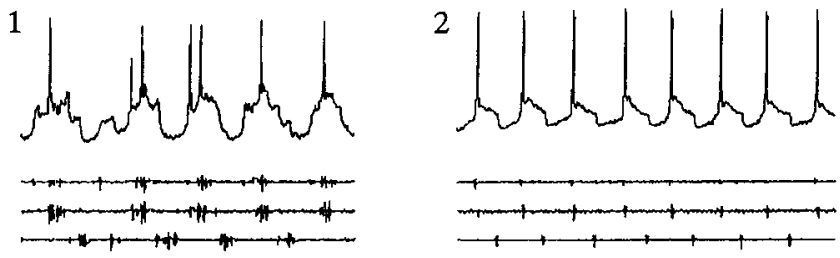

1

2
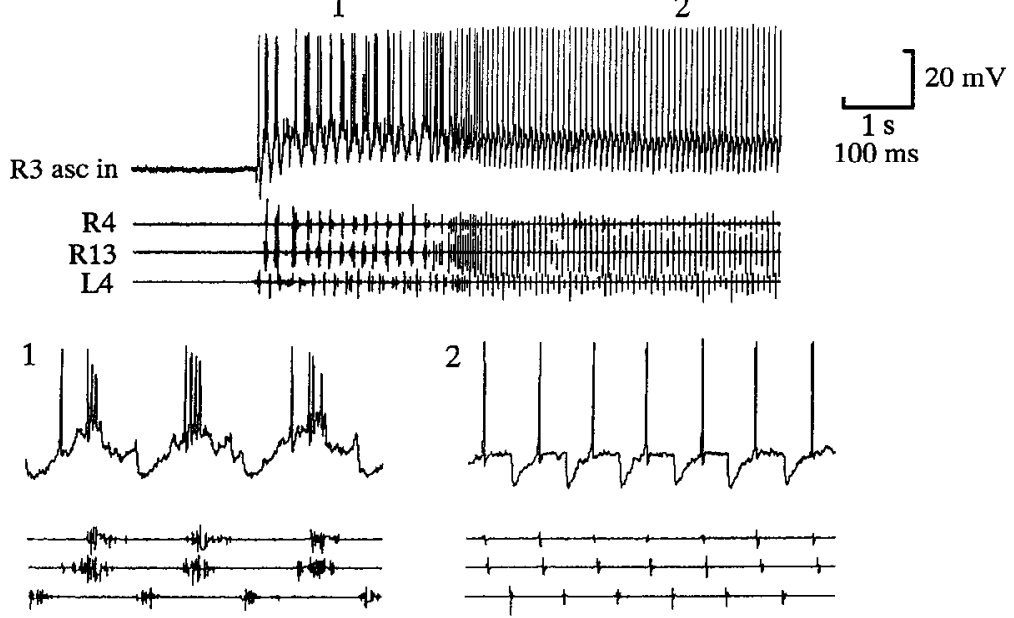

Figure 5. Activity of morphologically characterized premotor interneurons during struggling and swimming. All three neurons are from the right side. Each is drawn at low and high magnification following intracellular injection of HRP. Activity of part or all of a single episode is shown with expanded sequences of struggling (I), evoked by repetitive stimulation of the skin, and subsequent swimming (2). $A$, Descending interneuron from the third postotic segment $(R 3$ desc in) characterized by its medial position, multipolar soma, and ipsilateral descending axon. This neuron fired during struggling and on some cycles of swimming. $B$, Commissural interneuron from the seventh segment $(R 7$ com in) characterized by its medial position, unipolar soma, and axon that crosses the spinal cord, dividing into an ascending and descending branch. This neuron fired during both 
$A$
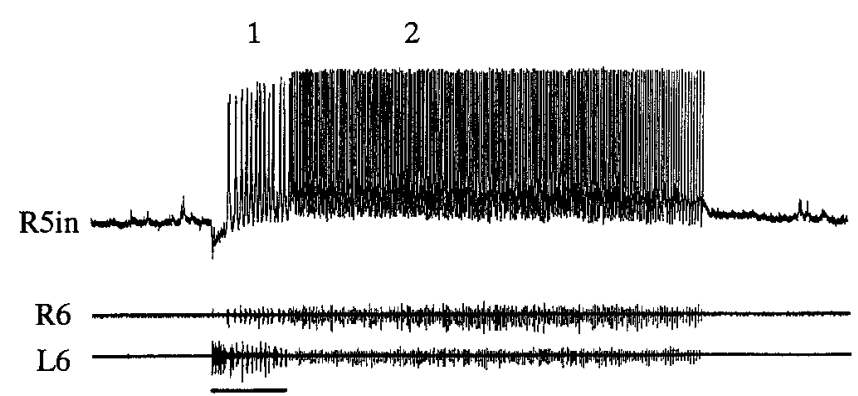

$B$

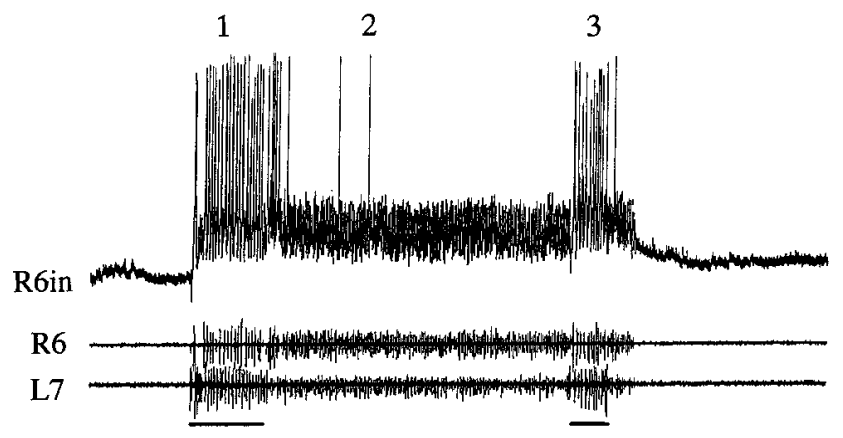

1
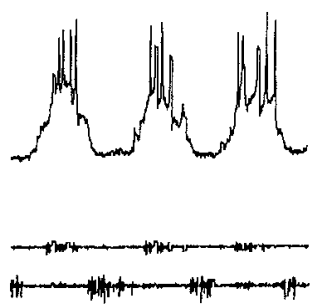

2
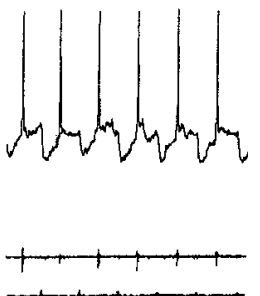

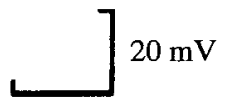

$4 \mathrm{~s}$

$200 \mathrm{~ms}$
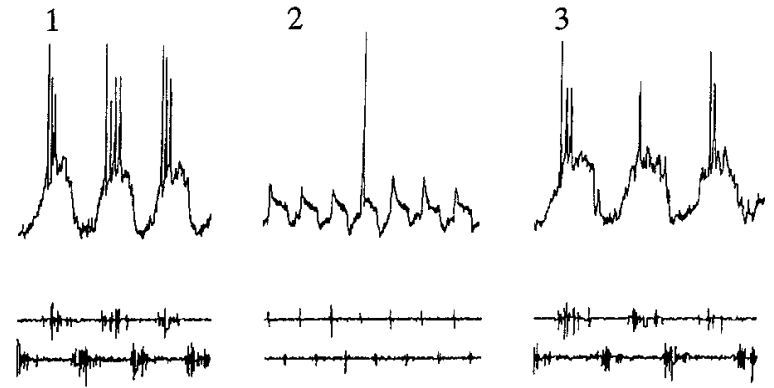

Figure 6. Spike activity in premotor interneurons during swimming and struggling. Struggling was evoked by repetitive electrical stimulation of the skin (indicated by horizontal bars). $A$, Intracellular recording from a presumed interneuron on the right side of the fifth postotic segment ( $R 5$ in) together with motor root recordings from the two sides $(R 6, L 6)$. The neuron fired both during struggling (expanded in $I)$ and swimming (expanded in 2). Note the repetitive firing during struggling and single spikes during swimming. $B$, Second presumed interneuron (R6in) recorded in a different embryo. This neuron fired repetitively during struggling (expanded in 1 and 3 ) but on few $(<10 \%)$ cycles during swimming (expanded in 2$)$.

of these neuronal classes are therefore involved uniquely in one or other behavior; all three classes may contribute to both swimming and struggling.

If many of the same premotor interneurons are involved in both swimming and struggling, do additional neurons become active during struggling, and if so, which? One possible difference between the circuitry for struggling and that for swimming was the addition of new neuronal classes. Because of the small total number of neuronal classes in the spinal cord, there were in fact only three candidates: the Rohon-Beard sensory neurons and the two classes of dorsolateral sensory interneurons. All three of these can be distinguished by physiological criteria from other neuronal types, and none of them normally fire during swimming (Clarke and Roberts, 1984; Clarke et al., 1984; Roberts and Sillar, 1991). It now seems that these neurons also do not participate in struggling. Direct recording has shown that neither the Rohon-Beard sensory neurons themselves, other than those that are stimulated directly via their peripheral neurites in the skin, nor dorsolateral commissural sensory interneurons are rccruitcd during struggling. The dorsolateral commissural interneurons, which are the more numerous of the two classes of spinal sensory interneurons (Roberts and Clarke, 1982), were previously considered likely candidates (Soffe, 1991b). They receive strong excitation from sensory Rohon-Beard neurons, which fire during repetitive stimulation of the skin to evoke struggling, and therefore it seemed highly likely that dorsolateral commissural interneurons would be driven to fire during struggling (Soffe, 1991b). This was an attractive possibility since active dorsolateral commissural interneurons would be in a position to relay excitation between the two sides of the spinal cord. However, at least in part because of strong glycinergic inhibition, they do not fire during struggling and are not, therefore, recruited to the struggling circuitry. It remains possible that choicc of recording site selected against active neurons being encountered in this study. However, this is unlikely since Rohon-Beard neurons make widespread output synapses via their long central axons and, similarly, dorsolateral commissural interneurons receive excitation from Rohon-Beard neurons in a wide variety of regions of the cord (Clarke et al., 1984; Sillar and Roberts, 1988). More recordings will be required to determine whether, as seems likely, the less numerous dorsolateral ascending interneurons are similarly inhibited during struggling. They are inhibited during swimming like dorsolateral commissural interneurons, though at midcycle (Roberts and Sillar, 1991).

If there is indeed no recruitment of new neuronal classes, any additional neurons that fire during struggling and could therefore

struggling and swimming. $C$. Ascending interneuron from the third segment ( $R 3$ asc in) characterized by its rather deep medioventral position, unipolar soma, and ascending axon (note also a short descending branch; neither axon shown at low magnification). This neuron fired during both struggling and swimming. 


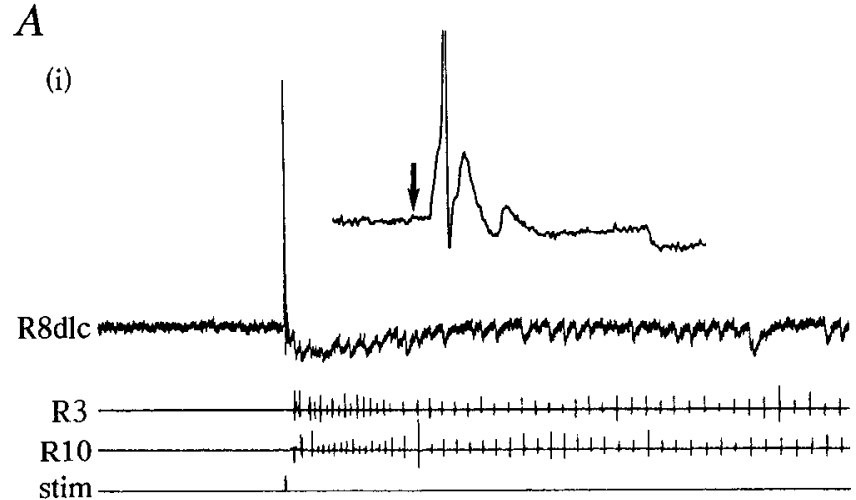

$B$

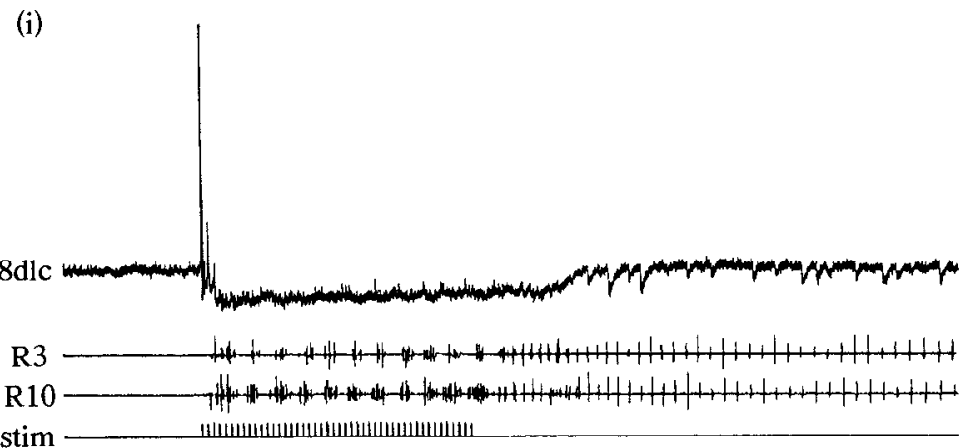

(ii)

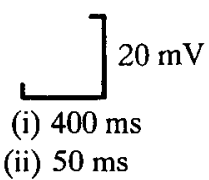

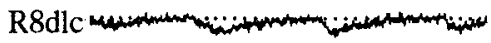

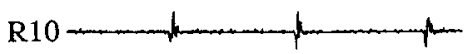

(ii)

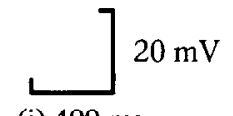

(i) $400 \mathrm{~ms}$

(ii) $100 \mathrm{~ms}$

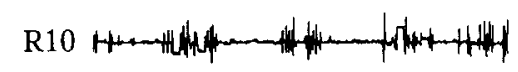

Figure 7. Activity of a dorsolateral commissural sensory interneuron during struggling and swimming: intracellular recording from an eighth segment neuron $(R 8 d l c)$. $A: i$, Single 1-msec-duration clectrical stimulus applicd to the skin cvokcd a short-latency EPSP driving a spike (expanded in inset, stimulus at arrow) followed by an episode of swimming during which the neuron received rhythmic IPSPs. $i i$, These IPSPs were on-cycle. $B: i$, Repetitive stimulation evoked a period of struggling followed by swimming. The dorsolateral commissural interneuron still only fired a single spike to the first stimulus. $i i$, During struggling, the neuron was hyperpolarized (resting potential between episodes shown is dotted).

constitute part of the circuitry must be from classes that already participate in swimming. In this study, nearly all motoneurons and premotor interneurons fired during struggling, about $30 \%$ more than during swimming. Besides not normally firing during swimming, these extra neurons were not distinct from other motoneurons and premotor interneurons. They shared the same pattern of alternate excitation and inhibition, which is characteristic of motoneurons and premotor interneurons during swimming and distinguishes them from sensory neurons and sensory interneurons. From the evidence presented here, the conclusion is that more of the same neurons rather than different neurons participate during struggling.

In drawing the above conclusion, I have assumed that the spinal cord neuronal classes currently recognized (Roberts and Clarke, 1982) are broadly homogeneous. Clearly, differences like size mean that this will not be entirely true. However, what anatomical, physiological, and pharmacological evidence there is has failed to highlight any substantial heterogeneity within neuronal classes. For example, commissural interneurons have been defined as a neuronal class on the basis of morphology (Roberts and Clake, 1982). They were subsequently shown to be the only neurons to express glycine immunoreactivity, and in appropriate numbers to suggest that all members of this morphological neuronal class are glycinergic (Dale et al., 1990). The observation that some neurons within a class may not fire during swimming while others do could be a reflection of heterogeneity in cellular properties, such as magnitude of $\mathrm{K}^{+}$currents and hence spike threshold, but could also result from unequal synaptic drive. Further recordings will be required to determine whether the assumption of broad homogeneity is justified or whether the neurons recruited during struggling have properties that distinguish them from those that also fire regularly during swimming.

\section{The switch from swimming to struggling}

If struggling and swimming do indeed involve the same classes of premotor interneurons, then, to this extent, essentially a single set of circuitry underlies the two behaviors. This single set of circuitry can somehow generate two quite different motor patterns that are distinct in their range of cycle periods, pattern of discharge on each cycle, and direction of longitudinal coordination. Getting and Dekin (1985) have distinguished three possible mechanisms for switching within neural networks: changes in the way sensory information impinges on the system, changes in functional synaptic interactions, and changes in intrinsic membrane properties.

The pattern of sensory discharge can clearly determine the output from the Xenopus embryo spinal circuitry in a way like that for escape or swimming responses in Tritonia (Getting and Dekin, 1985). The most obvious correlate of the switch to struggling in Xenopus is the recruitment of more premotor interneurons (and motoneurons). This could itself drive the motor pat- 
(i) $1 \mu \mathrm{M}$ strychnine
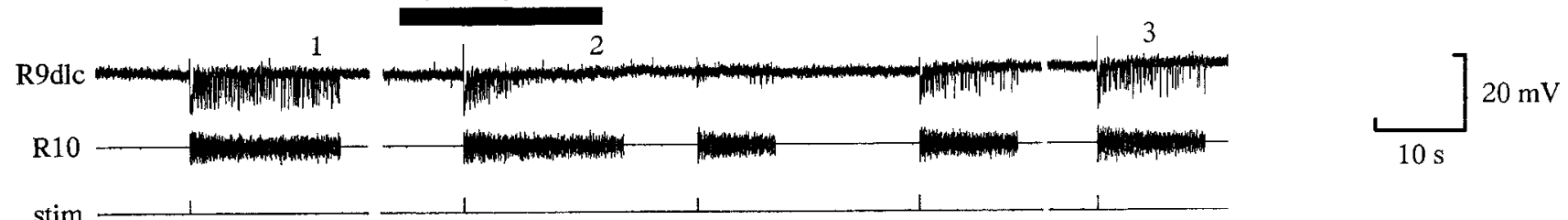

(ii)

1

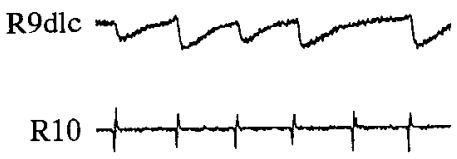

2

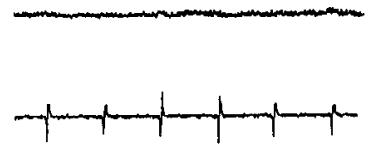

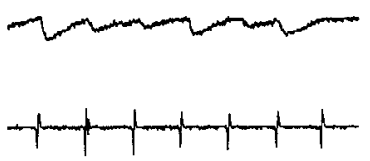

$100 \mathrm{~ms}$

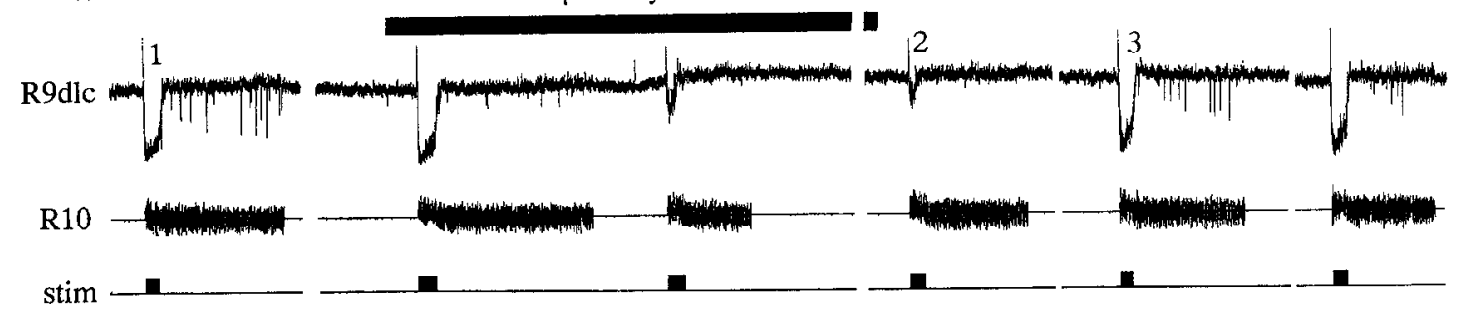

(ii)

1

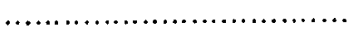

R9dlc

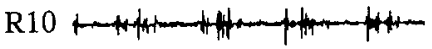

2
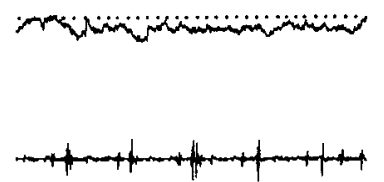

3
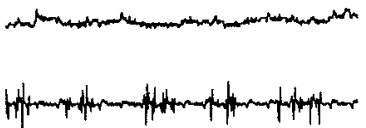

Figure 8. Local application of strychnine to a dorsolateral commissural interneuron during swimming and struggling: intracellular recording from a ninth segment neuron $(R 9 \mathrm{dlc})$ together with nearby motor root activity $(R 10)$. A:i, Five episodes of swimming, each evoked by a single stimulus (stim). Rhythmic IPSPs were reversibly blocked by local application of $1 \mu \mathrm{M}$ strychnine. $i i$, Expanded traces before (l), during (2), and after (3) strychnine application. $B: i$, Six episodes each starting with a sequence of struggling, evoked by repetitive stimulation, followed by swimming. Inhibition during struggling, producing a strong hyperpolarization at the start of each episode, was reversibly antagonized by $1 \mu \mathrm{M}$ strychnine. Notice that the IPSPs during swimming in each episode were less frequent following struggling than during episodes of swimming alone $(A, i)$. $i i$, Expanded sequences of struggling before (1), during (2), and after (3) strychnine application.

tern change from swimming to struggling. Alternatively, the change could result from direct or indirect modulation of synaptic or cellular propcrtics during repetitive sensory discharge. Such modulation can have profound effects on patterns of output in other motor systems (e.g., Katz and Harris-Warrick, 1991).

It seems unlikely that simple recruitment of more presynaptic neurons would produce the repetitive firing seen during struggling. Increasing the size of superthreshold depolarizing steps or depolarizing neurons during swimming does not normally lead to an increase in firing (as it can during struggling; see Fig. 2). However, the change from single to repetitive firing could be produced by modulation of membrane properties. Injection of $\mathrm{Cs}^{+}$into neurons both in vivo (Soffe, 1990) and in vitro (Dale, 1991) can produce repetitive firing, presumably by weakening $\mathrm{K}^{+}$conductances. Similar modulation of $\mathrm{K}^{+}$currents could occur during struggling, where it could additionally alter spike threshold and thus play a part in the recruitment of extra neurons.
Cycle periods during struggling are generally longer than during swimming. Simulation studies of the swimming pattern in Xenopus embryos highlight the time course of the midcycle IPSPs as "primary determinants" of cycle period (Roberts and Tunstall, 1990). They also suggest that period is "relatively independent of PSP amplitudes once critical levels have been exceeded." It remains to be established how closely these findings reflect the real mechanisms underlying swimming and whether similar conclusions apply also to struggling. Importantly, cycle periods for swimming and struggling overlap such that, for some periods (around 100-120 msec), the circuitry in a single embryo can produce either swimming or struggling output. Generation of activity at these cycle periods is therefore partly independent of which pattern the circuitry is producing, and therefore independent of whether or not neurons are firing repetitively, and whether or not there is a high level of synaptic drive.

The head-to-tail pattern of longitudinal coordination seen 
during swimming may result from a longitudinal gradicnt of "excitability" through which rostral neurons reach spike threshold sooner on each cycle than more caudal ones (Tunstall and Roberts, 1991). A similar proposal has been made for longitudinal coordination in the lamprey (Matsushima and Grillner, 1992). Supporting this proposal for Xenopus, the synaptic drive to motoneurons appears stronger rostrally than caudally (Tunstall and Roberts, 1993). During the switch to struggling, relative levels of "excitability" might be changed so that caudal neurons start firing first on each cycle. However, this would involve a major and position-specific change in synaptic drive, perhaps through modulation of specific synaptic connections. Alternatively, while caudal neurons may fire later than rostral ones during swimming primarily because of weaker excitation, they may fire sooner during struggling because of more rapid recovery from weaker inhibition. In this way, the pattern of longitudinal coordination would be excitation dominated during swimming and inhibition dominated during struggling. Blocking glycinergic inhibition can indeed disrupt struggling while leaving swimming apparently unaffected. However, this may simply be a reflection of a generally greater importance of inhibition during struggling.

\section{The output from sensory Rohon-Beard neurons}

A problem still to be resolved is the route by which RohonBeard neurons drive the struggling pattern. Rohon-Beard triggering of swimming apparently involves excitation of dorsolateral commissural sensory interneurons (Clarke and Roberts, 1984). Since only brief firing in Rohon-Beard neurons and dorsolateral commissural interneurons is required to trigger longlasting swimming activity, neither cell type need fire during swimming. However, repetitive activity in Rohon-Beard neurons must somchow drive spinal cord circuitry in a maintained way during struggling evoked by trunk skin stimulation. Since dorsolateral commissural interneurons apparently do not fire, some other route must exist. Rohon-Beard neurons could directly excite descending interneurons, some of which have dendrites sufficiently dorsal in the spinal cord to contact RohonBeard axons in the dorsal part of the marginal zone (Roberts and Clarke, 1982). However, such contacts remain to be demonstrated physiologically and anatomically.

\section{References}

Bekoff A, Nusbaum MP, Sabichi AC, Clifford M (1987) Neural control of limb coordination. I. Comparison of hatching and walking motor output patterns in normal and deafferented chicks. J Neurosci 7:23202330.

Berkinblit MB, Deliagina TG, Feldman AG, Gelfand IM, Orlovsky GN (1978) Generation of scratching. II. Nonregular regimes of generation. J Neurophysiol 41:1058-1069.

Clarke JDW, Roberts A (1984) Interneurones in the Xenopus embryo spinal cord: sensory excitation and activity during swimming. J Physiol (Lond) 354:345-362.

Clarke JDW, Hayes BP, Hunt SP, Roberts A (1984) Sensory physiology, anatomy and immunohistochemistry of Rohon-Beard neurones in embryos of Xenopus laevis. J Physiol (Lond) 348:511-525.

Dale N (1985) Reciprocal inhibitory interneurones in the Xenopus embryo spinal cord. J Physiol (I ond) 363:61-70.

Dale N (1991) The isolation and identification of spinal neurons that control movement in the Xenopus embryo. Eur J Neurosci 3:10251035.

Dale N, Roberts A (1984) Excitatory amino acid receptors in Xenopus embryo spinal cord and their role in the activation of swimming. $J$ Physiol (Lond) 348:527-543.

Dale N, Roberts A (1985) Dual-component amino-acid-mediated syn- aptic potentials: excitatory drive for swimming in Xenopus embryos. J Physiol (Lond) 363:35-59.

Dale N, Roberts A, Ottersen OP, Storm-Mathisen J (1986) Inhibitory neurones of a motor pattern generator in Xenopus revealed by antibodies to glycine. Nature 324:255-257.

Dale N, Roberts A, Ottersen OP, Storm-Mathisen J (1987) The morphology and distribution of 'Kolmer-Agduhr cells', a class of cerebrospinal-fluid-contacting neurones revealed in the frog embryo spinal cord by GABA immunocytochemistry. Proc R Soc Lond [Biol] 232:193-203.

Dale N, Roberts A, Soffe SR (1990) The anatomy, development, physiology and role of glycinergic neurones in the Xenopus embryo spinal cord. In: Glycine neurotransmission (Ottersen OP, Storm-Mathisen J, eds), pp 329-353. Chichester: Wiley.

Gelfand IM, Orlovsky GN, Shik ML (1988) Locomotion and scratching in tetrapods. In: Neural control of rhythmic movements in vertebrates (Cohen AH, Rossignol S, Grillner S, eds), pp 167-199. New York: Wiley.

Getting PA (1989) Emerging principles governing the operation of neural networks. Annu Rev Neurosci 12:185-204.

Getting PA, Dekin MS (1985) Tritonia swimming: a model system for integration within rhythmic motor systems. In: Model neural networks and behavior (Selverston AI, ed), pp 3-20. New York: Plenum.

Grillner S, Wallen P, Brodin L, Lansner A (1991) Neuronal network generating locomotor behaviour in lamprey: circuitry, transmitters, membrane properties, and simulation. Annu Rev Neurosci 14:169199.

Heitler WJ (1985) Motor programme switching in the crayfish swimmeret system. J Exp Biol 114: 521-549.

Hennig RM (1989) Neuromuscular activity during stridulation in the cricket Teleogryllus commodus. J Comp Physiol 165:837-846.

Hennig RM (1990) Neuronal control of the forewings in two different behaviours: stridulation and flight in the cricket, Teleogryllus commodus. J Comp Physiol [A] 167:617-627.

Jordan LM (1983) Factors determining motoneuron rhythmicity during fictive locomotion. In: Neural origin of rhythmic movements (Roberts A, Roberts BL, eds), pp 423-444. Cambridge: Cambridge UP.

Kahn JA, Roberts A (1982a) The central nervous origin of the swimming motor pattern in embryos of Xenopus laevis. J Exp Biol 99:185196.

Kahn JA, Roberts A (1982b) The neuromuscular basis of rhythmic struggling movements in cmbryos of Xenopus laevis. J Exp Biol 99: 197-203.

Kahn JA, Roberts A, Kashin SM (1982) The neuromuscular basis of swimming movements in embryos of the amphibian Xenopus laevis. J Exp Biol 99:175-184.

Katz PS, Harris-Warrick RM (1991) Recruitment of crab gastric mill neurons into the pyloric motor pattern by mechanosensory afferent stimulation. J Neurophysiol 65:1442-1451.

Matsushima T, Grillner S (1992) Neural mechanisms of intersegmental coordination in lamprey-local excitability changes modify the phase coupling along the spinal cord. J Neurophysiol 67:373-388.

Meyrand P, Simmers J, Moulins M (1991) Construction of a patterngenerating circuit with neurons of different networks. Nature 351:6063.

Mortin LI, Stcin PSG (1989) Spinal cord scgments containing kcy elements of the central pattern generators for three forms of scratch reflex in the turtle. J Neurosci 9:2285-2296.

Nieuwkoop PD, Faber J (1956) Normal tables of Xenopus laevis (Daudin). Amsterdam: North-Holland.

Ramirez JM, Pearson KG (1988) Generation of motor patterns for walking and flight in motoneurons supplying bifunctional muscles in the locust. J Neurobiol 19:257-282.

Roberts A (1978) Pineal eye and behaviour in Xenopus tadpoles. Nature 273:737-738.

Roberts A (1989) The neurons that control axial movements in a frog embryo. Am Zool 29:53-63.

Roberts A, Clarke JDW (1982) The neuroanatomy of an amphibian embryo spinal cord. Philos Trans R Soc Lond [Biol] 296:195-212.

Roberts A, Sillar KT (1991) Characterization and function of spinal excitatory interneurons with commissural projections in Xenopus laevis embryos. Eur J Neurosci 2:1051-1062.

Roberts A, Tunstall MJ (1990) Mutual re-excitation with post-inhibitory rebound: a simulation study on the mechanisms for locomotor 
rhythm generation in the spinal cord of Xenopus embryos. Eur $\mathbf{J}$ Neurosci 2:11-23.

Roberts A, Soffe SR, Dale N (1986) Spinal interneurones and swimming in frog embryos. In: Neurobiology of vertebrate locomotion (Grillner S, Stein PSG, Stuart D, Forssberg H, Herman RM, eds), pp 279-306. London: Macmillan.

Robertson GA, Mortin LI, Keifer J, Stcin PSG (1985) Threc forms of the scratch reflex in the spinal turtle: central generation of motor patterns. J Neurophysiol 53:1517-1534.

Sillar KT, Roberts A (1988) Unmyelinated cutaneous afferent neurones activate two types of excitatory amino acid receptor in the spinal cord of Xenopus laevis embryos. J Neurosci 8:1350-1360.

Sillar KT, Roberts A (1992) Phase-dependent modulation of a cutaneous sensory pathway by glycinergic inhibition from the locomotor rhythm generator in Xenopus embryos. Eur J Neurosci 4:1022-1034.

Soffe SR (1989) Roles of glycinergic inhibition and $N$-methyl-D-aspartate receptor-mediated excitation in the locomotor rhythmicity of one half of the Xenopus embryo CNS. Eur J Neurosci 1:561-571.

Soffe SR (1990) Active and passive membrane properties of spinal cord neurons which are rhythmically active during swimming in Xenopus embryos. Eur $\mathbf{J}$ Neurosci 2:1-10.

Soffe SR (1991a) Neuronal mechanisms for swimming in Xenopus embryos. In: Locomotor neural mechanisms in arthropods and ver- tebrates (Bush BMH, Armstrong DM, eds), pp 61-72. Manchester: Manchester UP.

Soffe SR (1991b) Triggering and gating of motor responses by sensory stimulation: behavioural selection in Xenopus embryos. Proc R Soc Lond [Biol] 246:197-203.

Soffe SR, Roberts A (1982a) Activity of myotomal motoneurons during fictive swimming in frog cmbryos. J Neurophysiol 48:1274-1278.

Soffe SR, Roberts A (1982b) Tonic and phasic synaptic input to spinal cord motoneurons during fictive locomotion in frog embryos. J Neurophysiol 48:1279-1288.

Soffe SR, Clarke JDW, Roberts A (1984) Activity of commissural interneurones in spinal cord of Xenopus embryos. J Neurophysiol 51: $1257-1267$.

Tunstall MJ, Roberts A (1991) Longitudinal coupling of motor output during swimming in Xenopus embryos. Proc R Soc Lond [Biol] 244: 27-32.

Tunstall MJ, Roberts A (1993) A longitudinal gradient of synaptic drive in the spinal cord of Xenopus embryos and its role in coordination of swimming. J Physiol (Lond), in press.

Weimann JM, Meyrand P, Marder E (1991) Neurons that form multiple pattern generators: identification and multiple activity pattcrns of gastric/pyloric neurons in the crab stomatogastric system. J Neurophysiol $65: 111-122$. 